\title{
Comfortable seating: the influence of seating comfort and acoustic comfort on customers' experience of hospitality in a self-service restaurant
}

\author{
Ruth Pijls ${ }^{\mathrm{a},}{ }^{*}$, Mirjam Galetzka $^{\mathrm{b}}$, Brenda H. Groen ${ }^{\mathrm{a}}$, Ad T.H. Pruyn $^{\mathrm{b}}$ \\ ${ }^{a}$ Hospitality Business School, Saxion University of Applied Sciences, P.O. Box 70.000, 7500, KB Enschede, the Netherlands \\ $\mathrm{b}$ Faculty of Behavioural Management \& Social Sciences, Department of Communication Sciences, University of Twente, \\ P.O. Box 217, 7500, AE Enschede, the Netherlands
}

\begin{abstract}
Does comfort in a restaurant influence people's experienced hospitality? Effects of seating comfort and acoustic comfort on the experience of hospitality were examined by means of a $2 \times 2$ between subjects experiment among 262 customers of a self-service restaurant, using the EH-scale measuring the experiential factors care, comfort and inviting. In line with theory on embodiment, MANOVA and mediation analysis showed that comfortable seating positively influences mental comfort, which subsequently increases the experience of hospitality (comfort factor). Extra ambient sound (acoustic discomfort) cancels out this effect. Also, people's desire to sit matters: people with a low desire to sit interpret comfortable seats as more caring instead of comfort. Regarding the discussion on (dis)comfort: seating comfort, not discomfort, accounted for the effects. Altogether, the hospitality experienced in a restaurant may be enhanced by offering comfortable seats, making customers feel more comfortable, physically and mentally.
\end{abstract}

Keywords: comfort, seating, hospitality, embodiment, service environment

\subsection{Introduction}

Service organisations increasingly recognize the importance of hospitality for customers' evaluation of their services. Thus far, most attention has been paid to understanding and measuring hospitable behaviour of service staff (e.g. Ariffin \& Maghzi, 2012; Blain \& Lashley, 2014; Tasci \& Semrad, 2016). However, it is widely accepted that besides staff behaviour, also ergonomic and environmental attributes play a role in people's experience (Ahola \& Mugge, 2017; Berry, Wall, \& Carbone, 2006; Bitner, 1992; Brunner-Sperdin, Peters, \& Strobl, 2012; Ladeira, Costa, \& Santini, 
2013). This is likely to apply also to the experience of hospitality. Pijls, Groen, Galetzka and Pruyn (2017) developed a scale (EH-scale) for measuring the three factors of the experience of hospitality in service environments (care, comfort and inviting), incorporating also physical aspects of the servicescape.

Research has shown that most abstract mental concepts are metaphorically based on concrete physical experiences (Asch, 1958; Murphy, 1996; Williams, Huang \& Bargh, 2009). According to this theory of embodiment, attributes we perceive with our senses result in bodily sensations, such as warmth and weight, which in turn affect our mental state. Something that is physically heavy, for instance, is metaphorically associated with concepts of seriousness and importance (Ackerman, Nocera, \& Bargh, 2010), and physical warmth is associated with emotional warmth and affection (Lakoff \& Johnson, 1980). Those concrete physical perceptions may help to define service elements that contribute to a hospitable experience.

Thus far, no research has been published on the role of bodily sensations in the experience of hospitality. The present study focuses on the comfort factor of the experience of hospitality. Based on embodied cognition theory we expect a relationship between the physical, bodily perception of comfort and the mental experience of comfort (feeling comfortable and relaxed). In the present study the effect of seating comfort and auditory comfort on mental comfort as well as the experience of hospitality is studied in a service context.

\subsection{Physical comfort}

Comfort in indoor environments is predominantly determined by building-related factors (Frontczak \& Wargocki, 2011). Building-related factors consist of hardware aspects of the building and indoor environmental conditions. Hardware aspects refer to the type of building and room interior aspects such as seating comfort (Lam, Chan, Fong, \& Lo, 2011; Lucas, 2003; Wakefield \& Blodget, 1996). Indoor environmental conditions include thermal comfort (Rijal, Humphreys \& Nicol, Wagner, Gossauer, Moosmann, Cropp \& Leonhart, 2007), visual comfort (Ricciardi \& Buratti, 2018), acoustic comfort (Frontczak \& Wargocki, 2011; Ricciardi \& Buratti, 2018) and indoor air quality (Huizenga, Abbaszadeh, Zagreus \& Arens, 2006, Mokhtar, Zaoui, \& Aid, 2014). So, both seating comfort and acoustic comfort are factors influencing people's perceptions of comfort in indoor environments. 


\subsection{Seating comfort}

Most research on seating comfort has been done in the field of ergonomics and is mainly focussed on office and classroom seats, passenger seats in public transport and operator seats in cars and buses (i.e. Cascioli, Liu, Heusch, \& McCarthy, 2016; Fasulo, Naddeo, \& Capetti (2018); Looze, Kuijt-Evers, \& van Drieën, 2003). Studies in this field are mostly experimental studies evaluating various characteristics of seats. Seating comfort has also been studied in the context of services, particularly in restaurants (e.g. Kim \& Moon, 2009; Lee, Wang, \& Cai, 2015), casinos (e.g. Lam et al., 2011; Lucas, 2003; Wakefield \& Blodget, 1996) and at airports (e.g. Moon, Yoon, \& Han, 2017; Zheng, 2014). In these service-related studies seating comfort serves as one of the environmental service elements influencing satisfaction and loyalty, and it is usually evaluated after people's visit.

According to Lam et al. (2011) seating comfort refers to the level of physical (dis)comfort derived from the seating quality, and it is affected by the physical seat itself and by the distance between seats (Lee et al., 2015; Lucas, 2003; Wakefield \& Blodgett, 1996). Concerning the physical seat, the softness of the seats (such as seat padding and fabric materials) as well as the design of the seats (aesthetic design, armrests and backrests, seat dimensions) have been found to affect seating comfort (Branton \& Grayson, 1967; Floyd \& Ward, 1969; Mastrigt, Groenesteijn, Vink, \& Kuijt-Evers, 2017; Oborne, 1987).

With regard to the evaluation of seating comfort, debates are going on about whether comfort and discomfort are two opposites of a continuous scale, ranging from extreme discomfort to extreme comfort (e.g. Richards, 1980), or whether they are separate constructs (Helander \& Zhang, 1997; Hiemstra-van Mastrigt, Groenestein, Vink \& Kuijt-Evers, 2017; Zhang, Helander, \& Drury, 1996). Currently, the latter view receives most support. According to Zhang et al. (1996) the two are independent factors affected by different variables. Comfort is associated with feelings of relaxation and well-being, and can be influenced by, for example, the design and materials of seats. On the other hand, discomfort is associated with feelings of pain, soreness, numbness and stiffness, and is caused by physical constraints in the design. Vink (2005) also indicated that discomfort was more related to physical characteristics, whereas comfort was more related to experience, emotion, unexpected features, and luxury. Helander and Zhang (1997) performed a study in an office setting, measuring comfort and discomfort of several chairs at three moments during the day. They found that discomfort increases over time, and is independent of the design of the chair. The longer the time that people sat on a chair, the more discomfort they experienced. In contrast, comfort is regarded as time independent. People can immediately assess comfort factors when they sit down. 


\subsection{Acoustic comfort}

Acoustic comfort refers to "a state of contentment with acoustic conditions" (Frontczak \& Wargocki, 2011, p.925). Mokhtar et al. (2014) distinguish inside noise (equipment, moving, activities) and outside noise (transportation and neighbouring buildings). The type of the noise, sound levels and the frequency of sounds are sound characteristics that influence what people perceive as comfortable (Frontczak \& Wargocki, 2011).

Studies on the influence of sound sources on the acoustic comfort in restaurants are scarce (Chen \& Kang, 2017). Chen and Kang (2017) investigated acoustic comfort in two large dining spaces. They made a distinction between four types of sound sources: general background music, speech sound, activity sound (sounds of tableware, footsteps, food preparation) and mechanical noise (kitchen ventilators, the sound of elevators running and the friction sound of dining trolleys). Also, Lindborg (2016) developed a taxonomy of sound sources in restaurants. He divided sounds into three main categories, largely corresponding to Chen and Kang (2017). The first category, sound design, refers to sounds of nature, music and other sounds, such as machines and traffic. The second category, cuisine, consists of kitchen sounds. The third category, customers, refers to conversations (laughter, chatting, shouting), eating (glassware clinking, tableware clatter and eating/slurping), and crowd (talking, children, footsteps, chairs). Lindborg (2016) further concluded that people rate sounds of screeching chairs, kitchen washing sounds, clanking dishes, and footsteps as unpleasant. At the other hand cooking sounds, music and glassware (which produces more likeable sounds than metal tableware) are rated as pleasant.

Chen and Kang (2017) further found that the acoustic comfort of diners has an influence on the comfort evaluation of the overall dining environment, and background noise is an important factor affecting the acoustic comfort evaluation of diners.

\subsection{Comfort, embodiment and hospitality}

Although a link between physical and mental comfort seems evident, research on the embodiment of the mental concept of comfort has thus far not been reported in literature. Nevertheless, people are able to experience comfort both physically and mentally. Slater (1985) for example distinguished between a physical and a psychological component of comfort. Also da Silva Menegon, Vincenzi, Andrade, Barbetta, Merino, \& Vink (2017) makes a distinction between a physical and a psychological component. Therefore, we hypothesize, based on embodied cognition theory, that physical comfort (both physical seating comfort and physical acoustic comfort) triggers 
the mental concept of comfort. Since comfort is related to the experience of hospitality (Pijls et al., 2017), mental comfort in turn is expected to affect people's experience of hospitality.

\section{Aim of the study}

The present study explored the role of the embodied concept of comfort in the experience of hospitality. The study focused on the effect of two types of physical comfort, type of seat and acoustic comfort, on the experience of hospitality among customers of a self-service restaurant in an international furniture chain. Seating comfort was manipulated by the type of seat (a chair with seat support versus stool without seat support). It was expected that chairs would be perceived as physically more comfortable, which would lead to the mental experience comfort, and in turn result in an increased experience of hospitality. As mental comfort is conceptually related to the comfort factor of the experience of hospitality (Pijls et al., 2017), the effects are predominantly expected for this factor of the experience of hospitality. Acoustic comfort was manipulated by the ambient noise (playing or not playing extra kitchen noise on a speaker). It was expected that a lower level of ambient noise would be perceived as acoustically more comfortable, which would lead to the experience of more mental comfort, and in turn result in an increased experience of hospitality.

Furthermore, the effects of physical comfort may depend on individual characteristics. For example, visitors of the restaurant may vary in their desire to sit down and relax for a while. Depending on, amongst others, their physical condition and the time they have spent in the retail environment visitors may desire to sit down and take a rest. The higher their desire to relax, the more they are expected to appreciate a comfortable seat.

\section{Method}

\subsection{Design and participants}

A 2 (type of seat: chair versus stool) x 2 (ambient sound: presence versus absence of extra kitchen sound) between-subjects design was employed. 262 Native Dutch speaking adults who visited the restaurant of a self-service restaurant of a large furniture chain together with a maximum of three other adults participated in the experiment. To minimalize the effect of influence extra sounds, people with young children were excluded from the study. Children from primary and secondary school were not present, since the experiment took place during school time. Also people with a hearing impairment, physical impairment and extreme obesity were excluded from the study. 179 participants were female, mean age was 54.9 ( $S D=17.14)$, and except primary school $(2,3 \%)$, all levels of educational background were about equally represented. Participants were randomly assigned to the conditions of type of seat and ambient sound. The experiment took place on Tuesdays, Thursdays 
and Fridays, between 10 am and $4 \mathrm{pm}$, the period that there were relatively few families with young children. The area of the restaurant that was set apart for this study was either furnished with chairs or with stools. Half of the time the extra kitchen sound was played. The four conditions were equally distributed over the weekdays and time of the day to control for crowdedness, time and day of the week.

\subsection{Environmental manipulation}

Type of seat was manipulated by the type of seats in the restaurant. The selection of the furniture was based on a pre-test: 17 different seats were evaluated, by asking 20 to 25 visitors to rate the comfort of the seats on a seven-point scale. The two seats with the largest difference in the scores on the support and physical comfort were selected for the study (presented in Figure 1). The results of the pre-test showed that the perceived support of the chair with the backrest $(M=5.42, S D=1.16)$ was higher than perceived support of the stool without backrest $(M=2.97, S D=1.13, F(1,54)=63.52$, $\left.p<.001 \eta^{2=} .54\right)$. In addition, the physical comfort of the chairs $(M=5.44, S D=1.31)$ was rated higher than the physical comfort of the stools $\left(M=3.54, S D=0.91, F(1,54)=37.71, p<.001 \eta^{2=} .41\right)$. In particular the height and shape of the backrest and the absence of pressure point may cause physical discomfort. For the stool the reactions were mainly the lack of support because of the absence of a backrest and the round and relatively small surface of the seat of the stool. This refer to the seat characteristics seat dimensions and shape of the seat identified by Mastrigt, Groenesteijn, Vink, and Kuijt-Evers (2017).

Thus, people sat either on a chair with backrest (black, wood, seat height $44 \mathrm{~cm}$ ) or a stool without backrest (black, plastic seat with iron frame, seat height $45 \mathrm{~cm}$ ). The area in the restaurant that was set apart for the study comprised of 5 tables with each 2 seats, either chairs or stools.

Ambient sound was manipulated by playing or not playing extra background kitchen sound (sounds of bowls, plates and cutlery) in the area of the restaurant where the research took place. The manipulation was based on Lindborg (2016), who showed that people did not like kitchen washing sounds and clanking dishes. The sound was played using a JBL Flip3 Portable Bluetooth Speaker, hidden in a tube and placed in a corner on the floor, so that it seemed to originate from the kitchen. The distance between the speaker and the tables was 2 to 4 meters. Nobody commented that the sound was artificial. The sound level of the extra ambient sound was between 2 and $3 \mathrm{dBA}$ above the level of the natural ambient sound. Overall the sound level of ambient sound varied from 56.0 to 64.4 dBA. 


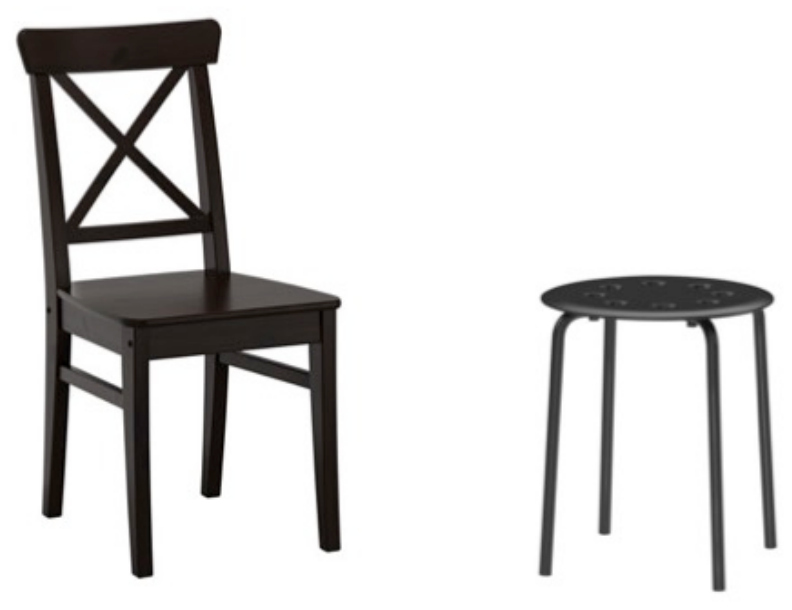

Figure 1. The two types of seats, with seat backrest (left) and without backrest (right).

\subsection{Measures}

For all statements in this study the participants were required to indicate on a seven-point Likert scale the degree to which they agreed with the statement (ranging from strong disagreement to strong agreement).

Experience of hospitality. The experience of hospitality was measured by the 13-item EH-Scale (Pijls, Groen, Galetzka \& Pruyn, 2017) with three factors. The care factor comprised seven items measuring the experience of servitude, empathy and acknowledgement (Cronbach's $\alpha=.93$ ). The factor comfort was measured by three items on feeling comfortable, at ease and relaxed (Cronbach's $\alpha=.82$ ). The inviting factor consisted of three items on experiencing openness, freedom and feeling invited (Cronbach's $\alpha=.75$ ). Cronbach's alpha for the overall experience of hospitality (13 items) was .92.

(Dis)comfort. Physical (dis)comfort was measured by the physical seating comfort, physical seating discomfort, physical acoustic comfort and physical acoustic discomfort. Furthermore, in the present study a separate scale was composed for measuring mental comfort. A factor analysis (PCA) was performed on all comfort-related items (see appendix A for the rotated factor matrix). After removing 6 items with low factor loadings and cross loadings, the analysis resulted in the 5 factors described above: physical seating comfort, physical seating discomfort, physical acoustic comfort, physical acoustic discomfit and a separate factor mental comfort. For the complete survey questions on (dis)comfort see appendix B.

- Physical seating comfort and discomfort. Items for measuring the physical seating comfort were based on amongst others Helander and Zhang (1997) and da Silva Menegon et al. (2017). Three items ('stability', 'attractiveness' and 'new') were excluded because of low factor loadings (<.6), resulting in a 9-item scale (Cronbach's $\alpha=.94$ ). The 5-item measurement of physical seating 
discomfort was based on the discomfort factor of the Chair Evaluation Checklist developed by Helander and Zhang (1997). Because of low factor loadings (<.6) two items were excluded ('sore muscles', 'seating discomfort', resulting in a 3-item factor (Cronbach's $\alpha=.85$ ).

- Physical acoustic comfort and discomfort. The factor analysis again distinguished between acoustic comfort (pleasantness of the sound and comprehensibility, 2 items, Pearson correlation $\mathrm{r}=.34$ ), and acoustic discomfort (fatigue of the ambient sound, and to what degree participants heard and suffered from sounds from the kitchen, 3 items, Cronbach's $\alpha=.78$ ). One item (on the noisiness) was removed because of cross loading on both factors. Additionally, the average sound level (dBA) over periods of 20 to 30 minutes was measured using SafeNoise, an IPhone-app approved by the Dutch hearing foundation.

- Mental comfort. For measuring the experienced mental comfort, items were adopted from the well-being factor of the Chair Evaluation Checklist (CEC) developed by Helander and Zhang (1997), from the questionnaire for aircraft seating comfort (da Silva Menegon et al., 2017). Two items on resting and recovering were added. The six items formed a separate factor (Cronbach's $\alpha 6$-items $=.95)$.

- Desire to relax. To measure participants' desire to relax, participants were asked to what degree they wished to sit down for a while, felt physically tired and desired to relax their body (Cronbach's $\alpha=.86$ ).

Demographics. Gender, age, body height, weight and educational background were registered.

other measures. To avoid possible confounding effects, additional questions were asked about the seats and the restaurant (attractiveness, cleanliness, smell, perceived warmth, air flow, lighting and consumption of food and drinks). Also, the frequency of visit, the duration of the visit, the motivation for the visit and the type of drink and food (warm/cold) were reported. Furthermore, the indoor air temperature $\left({ }^{\circ} \mathrm{C}\right)$ and crowdedness were registered for each participant. Also the time between the handout and the return of the questionnaire was registered (this ranged from 10 to 39 minutes, with an average of 15 minutes).

\subsection{Procedure}

In the self-service restaurant of a large furniture chain, guests were randomly approached after check out and were asked to participate in a study on customers' restaurant experience. They were asked to take a seat in the area that was set apart for the study, and to use the restaurant as they intended (to eat/drink (71\%), to rest (13\%), to catch up (6\%) or for some other reason (10\%)). After a few minutes, they were handed out the questionnaire and were asked to individually fill it out during 
or after the consumption of their food and drinks. The participants mostly filled in the questionnaire either immediately after they received the questionnaire, or after their consumption of the food. To avoid order effects, half of the participants received version A (first the questions on physical comfort, then the questions on mental comfort), and the other half received version B (first the questions on mental comfort, then the questions on physical comfort). Participation took about 10 minutes. After filling out the questionnaire, the participants were thanked for their participation and received a food product.

\section{Results}

\subsection{Manipulation check}

First was checked whether the manipulations of physical comfort, type of seat and ambient sound, were successful. Regarding the type of seat, a one-way MANOVA showed significant results (Wilks's $\Lambda$ $\left.=.82, F(2,254)=27.55, p<.001, \eta^{2}=.18\right)$. The chairs were rated more comfortable $(M=4.76, S D=1.22)$ than the stools $\left(M=3.49, \mathrm{SD}=1.49 ; F(1,255)=54.83 ; p<.001 ; \eta^{2}=.17 ; 95 \% \mathrm{CI}[.928,1.600]\right)$. Also for discomfort results were significant. The stool was rated as more discomfortable $(M=3.37, S D=1.59)$ than the chair $\left(M=2.86, S D=1.43 ; F(1,255)=7.04 ; p<.01, \eta^{2}=.027 ; 95 \% \operatorname{CI}[.130, .876]\right)$.

Regarding the ambient sound, the MANOVA was significant (Wilks's $\Lambda=.52, F(3,244)=74.58$, $\left.p=>.001, \eta^{2}=.48\right)$. When the additional kitchen sound was played, the sound levels were higher $(M=61.63 \mathrm{dBA}, S D=1.57)$ than when no additional kitchen sound was played $(M=58.83 \mathrm{dBA}, S D=1.37$; $\left.F(1,246)=222.42 ; p<.001 ; \eta^{2}=.48 ; 95 \% \operatorname{CI}[2.435,3.176]\right)$. Further, with additional kitchen sound, the acoustic discomfort was higher $(M=3.52, S D=1.52)$ than without additional kitchen sound $(M=3.14$, $S D=1.39 ; F(1,246)=4.08 ; p<.05 ; \eta^{2}=.016 ; 95 \%$ CI$\left.[.009, .743]\right)$. However, for acoustic comfort no difference was found. Although extra kitchen noise led to more discomfort, it did not lead to less comfort; The average scores for acoustic discomfort were still low, and acoustic comfort scores were still high $(M=4.85 ; S D=1.23)$. Furthermore, although the difference between the conditions in sound levels $(2,81 \mathrm{dBA})$ was clearly different, the difference in acoustic discomfort between the two sound conditions, though significant, was not very large.

\subsection{Effects of type of seat and ambient sound}

First, the hypothesized direct effects of type of seat and ambient sound on the experience of hospitality were examined by performing a 2 x 2 MANOVA. Prior to the test the dependent variables were checked for normality. Although the Kolmogorov-Smirnov test was significant, indicating nonnormally distribution, skewness and kurtosis values were between -2 and +2 , which are considered 
acceptable (Field, 2013; George \& Mallery, 2010).

For type of seat the MANOVA was significant (Wilks's $\Lambda=.97, F(3,227)=2.61, p=.05, \eta^{2}=.033$ ). The univariate ANOVA's showed that the effect of type of seat on the comfort factor was significant $\left(F(1,229)=3.98, p<.05, \eta^{2}=.017 ; 95 \% \operatorname{CI}[.00, .621]\right)$. People who sat on the chair experienced more $\operatorname{comfort}\left(M_{\text {chair }}=5.51, S D=1.16\right.$, versus $\left.M_{\text {stool }}=5.20, S D=1.24\right)$ than people who sat on the stool. The effect of type of seat on the overall experience of hospitality $\left(F(1,229)=2.91, p=.09, \eta^{2}=.013 ; 95 \% \mathrm{CI}[-.041\right.$, $.565])$ and the care factor $\left(F(1,229)=2.94, p=.09, \eta^{2}=.013 ; 95 \% \operatorname{CI}[-.048, .687]\right)$ approached significance. Type of seat had no effect on the experience of inviting. For ambient sound no direct effects were found on the experience of hospitality, neither on the overall experience of hospitality, nor on the experience of care, comfort and inviting.

However, there was a significant interaction between type of seat and ambient sound on the comfort factor of the EH-scale $\left(F(1,229)=6.10, p<.05, \eta^{2}=.026 ; 95 \% \mathrm{CI}[.004, .621]\right)$. The interaction is presented in Figure 3. Simple effects analysis showed that the effect of type of seat on the experience of comfort only applied to the no-extra-sound-condition $\left(F(1,252)=10.36, p<.001, \eta^{2}=.039 ; 95 \%\right.$ CI[.263, 1.094]. Thus, the effect of the type of furniture on the experience of comfort only occurred when no extra kitchen sound was present; when exposed to extra kitchen noise, the difference in the experienced hospitality (comfort factor) that resulted from the comfort of the seats disappeared.

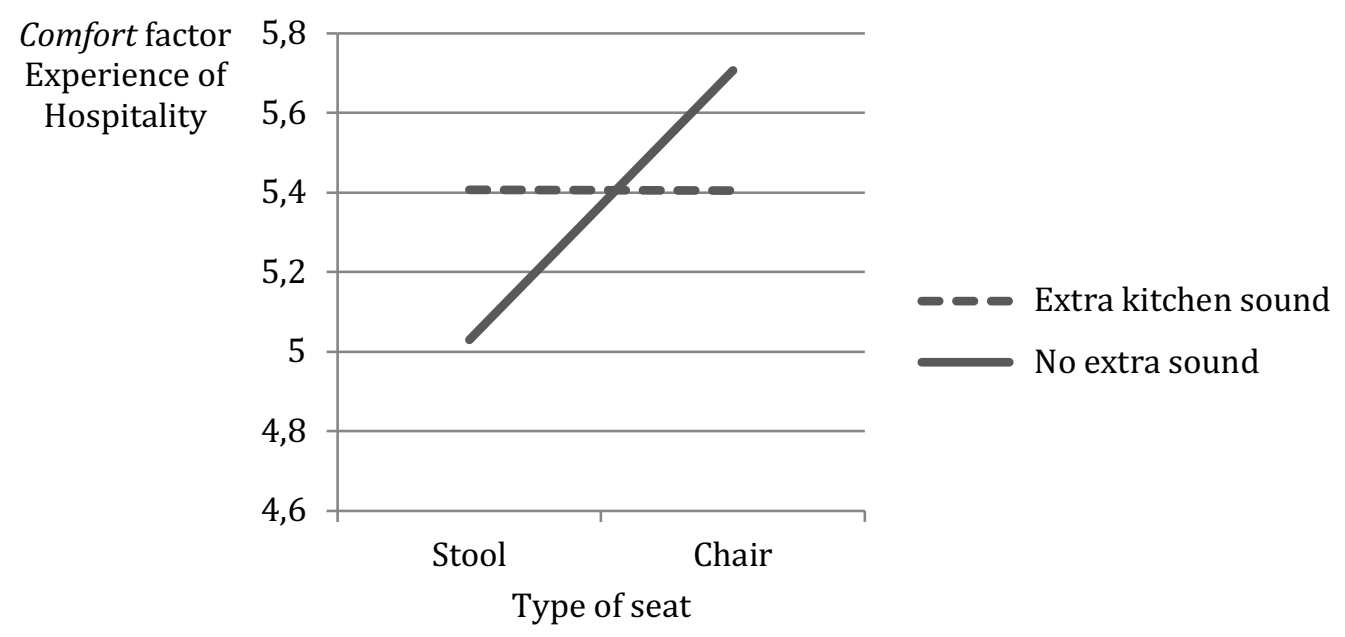

Figure 3. Interaction of type of seat $\mathrm{x}$ ambient sound on the comfort factor of the experience of hospitality.

As was expected, effects of type of seat and the interaction between type of seat and ambient sound were only found for the experience of hospitality, and not on the perceived attractiveness $\left(M_{\text {stool }}=4.91\right.$, 
$S D=1.31$, versus $\left.M_{\text {chair }}=4.96, S D=1.38\right)$ and the perceived cleanliness $\left(\left(M_{\text {stool }}=5.40, S D=1.29\right.\right.$, versus $\left.M_{\text {chair }}=5.35, S D=1.39\right)$. Furthermore, MANCOVA analysis revealed that the administered factors type of food (warm/cold), type of drink (warm/cold), indoor temperature, crowdedness, perceived airflow, lighting, frequency of visit, duration of visit and the motivation for the visit changed the effects of the type of seat and ambient sound on the experience of hospitality factors only in some cases to a minor extent.

In conclusion, in line with our expectations comfort of seating influences the comfort factor of people's experience of hospitality. The manipulation of ambient sound showed no direct effect on customers' experience of hospitality. The manipulation might have been too subtle. However, because of the significant interaction between type of seat and ambient sound on the comfort factor, ambient sound did have an impact on people's experience of hospitality.

\subsection{Mental comfort}

Next, it was examined whether mental comfort mediated the effects found for type of seat on the experience of comfort. Mediation analysis using SPSS PROCESS (Preacher \& Hayes, 2004; Zhao, Lynch $\&$ Chen, 2010) was performed to test the mediating role of the experienced mental comfort in the effect. The indirect effect was tested using a bootstrap estimation approach with 5000 samples (Preacher \& Hayes, 2004; Zhao, Lynch \& Chen, 2010). The direct effects of type of seat on the experience of hospitality was fully mediated by the experience of mental comfort; Indirect effects were found for type of seat on comfort ( $b=.31, S E=.096, C I=.1292, .4232$, see Figure 4), with 95\% confidence intervals, excluding 0 . When including mental comfort into the model, type of seat was no longer a significant predictor of the comfort factor of the EH-scale. The direct effects of type of seat on the overall experience of hospitality and on the care factor, that approached significance, were also fully mediated by the experience of mental comfort $(b=.30, S E=.095, C I=.1156, .4852$ and $b=.31, S E$ $=.096, C I=.1292, .5048$ respectively), with 95\% confidence intervals, excluding 0 .

Further, it already appeared that there was no direct effect of ambient sound on the experience of hospitality; mental comfort did not appear to be a mediator in this effect either. 


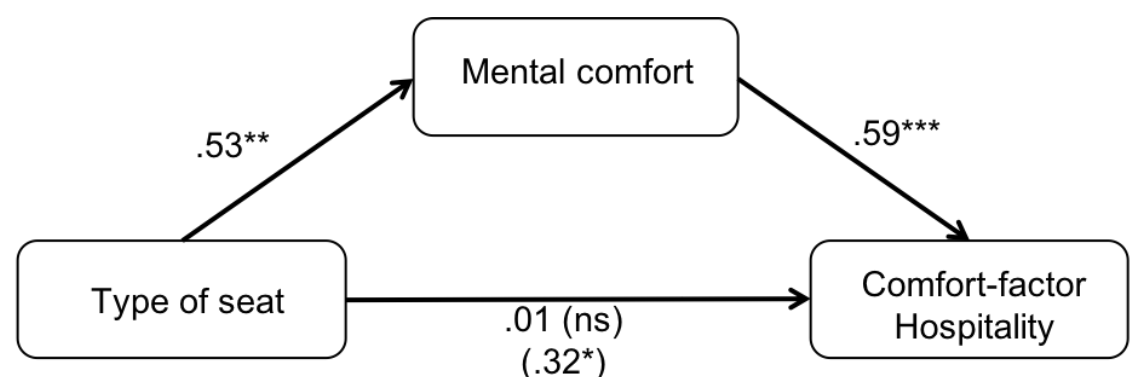

$\left(.32^{*}\right)$

Figure 4. Mediation analyses in the effects of type of seat on comfort with mental comfort as mediator. Note: unstandardized coefficients and significance values $\left({ }^{*} \mathrm{p}<.05,{ }^{* *} \mathrm{p}<.01,{ }^{* *} \mathrm{p}<.001\right)$ are reported. The unstandardized coefficients in brackets indicate the effect ignoring the mediator.

Thus, in line with what was expected, the type of seat increased the experience of comfort, via the mental comfort experienced in the restaurant. This provides support for embodied cognition as a mechanism underlying the effect of physical comfort on the experience of hospitality.

\subsection{Physical comfort and physical discomfort}

As in the literature seating comfort and seating discomfort were regarded as two separate constructs, mediation analysis was performed to examine to what extent the effect of type of seat on mental comfort can be explained by physical seating comfort and physical seating discomfort. Mediation analysis using SPSS PROCESS with three mediators (model 6) was performed to test the mediating role of physical seating comfort and physical seating discomfort in the effect of type of seating via mental comfort on the comfort factor of the experience of hospitality. The indirect effect was tested using a bootstrap estimation approach with 5000 samples (Preacher \& Hayes, 2004; Zhao, Lynch \& Chen, 2010). As Figure 5 shows, one indirect effect was found of type of seat on the comfort factor of the experience of hospitality via successively physical seating comfort and mental comfort, with 95\% confidence intervals, excluding $0(b=.32, S E=.072, C I=.1955, .3761)$. When including physical seating comfort, physical seating discomfort and mental comfort into the model, type of seat was no longer a significant predictor of the mental comfort indicating full mediation of physical seating comfort and mental comfort. Seating discomfort did not mediate the effect of type of seat on the experienced mental comfort and subsequently the experience of the comfort factor hospitality. 


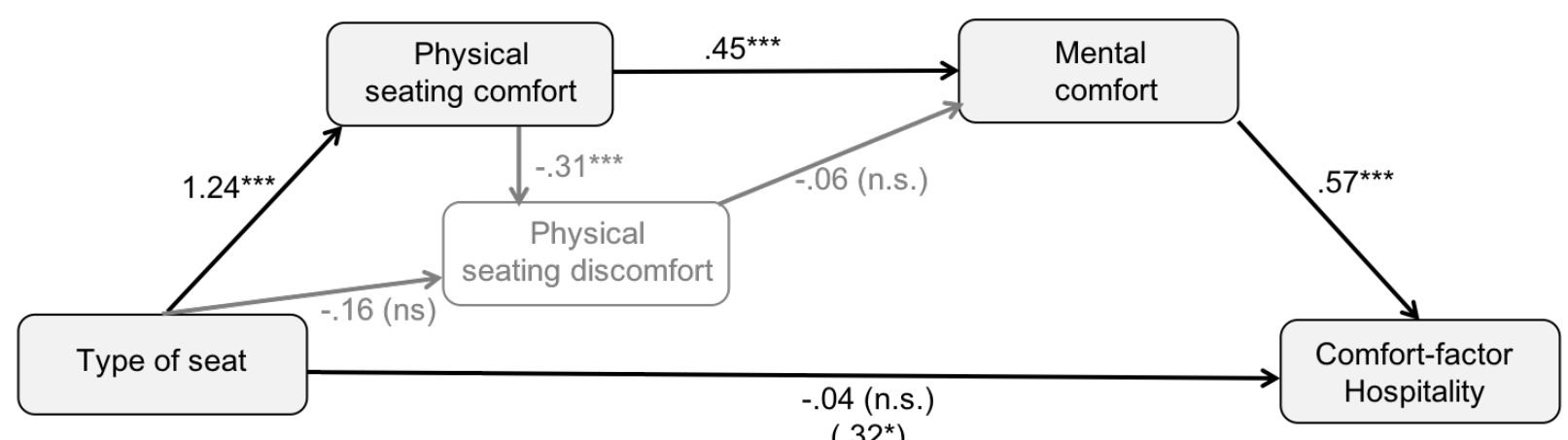

$\left(.32^{*}\right)$

Figure 5. Mediation analyses in the effects of type of seat on the comfort factor of the experience of hospitality with physical comfort, physical discomfort, and mental comfort as mediator.

Note: unstandardized coefficients and significance values $\left({ }^{*} \mathrm{p}<.05,{ }^{* *} \mathrm{p}<.01,{ }^{* * *} \mathrm{p}<.001\right)$ are reported. The unstandardized coefficients in brackets indicate the effect ignoring the mediator.

The different role of the two constructs in the effect of type of seat on the experience of hospitality provides additional support for the distinction between comfort and discomfort, next to the factor analyses that revealed physical seating comfort and physical seating discomfort as separate factors.

Because no effect was found of ambient sound on the experience of hospitality, the role of physical acoustic comfort and discomfort in the effect of ambient sound could not be determined.

\subsection{Desire to relax}

The role of the desire to relax on people's perception of physical comfort and the experience of hospitality was examined. Firstly, multiple regression analyses showed that, in line with others (i.e. Kamp, Kilincsoy, \& Vink, 2011; Mastrigt, Groenesteijn, Vink, \& Kuijt-Evers, 2017), the perceived physical comfort was related to the intentions of the subject. Regardless of the type of seat, the desire to sit significantly predicted the perceived discomfort of the restaurant seats (adjusted $R^{2}=.14, F$ $(1,256)=42.34, p<.001 ; \beta=.38, p<.001)$. The more people desired to sit, the more uncomfortable they perceived the seats.

To examine the moderating role of customers' desire to relax in the effect of type of seat on the experience of hospitality factors, moderation analysis was performed using SPSS PROCESS (Preacher \& Hayes, 2004). Desire to relax had no influence on the effect of type of seat on the experience of comfort.

However, incorporating Desire to relax (DR) into the model resulted in an effect of type of seat on the experience of care $\left(R^{2}=.04, F(3,240)=3.71, p<0.05\right)$. As can be seen in Figure 6 , for people with a low desire to relax (1 SD below mean) the experience of care in the restaurant was higher for people 
who sat on a chair than for people who sat on a stool $(b=.75, S E=.258, C I=.2438,1.2599)$. So people who do not really desire to sit interpret the presence of uncomfortable stools as a less caring gesture of the organization. For people with a medium or high desire to relax, the comfort of the seat did not affect their experience of care. For them the type of seat matters less; they are even happy with an uncomfortable stool.

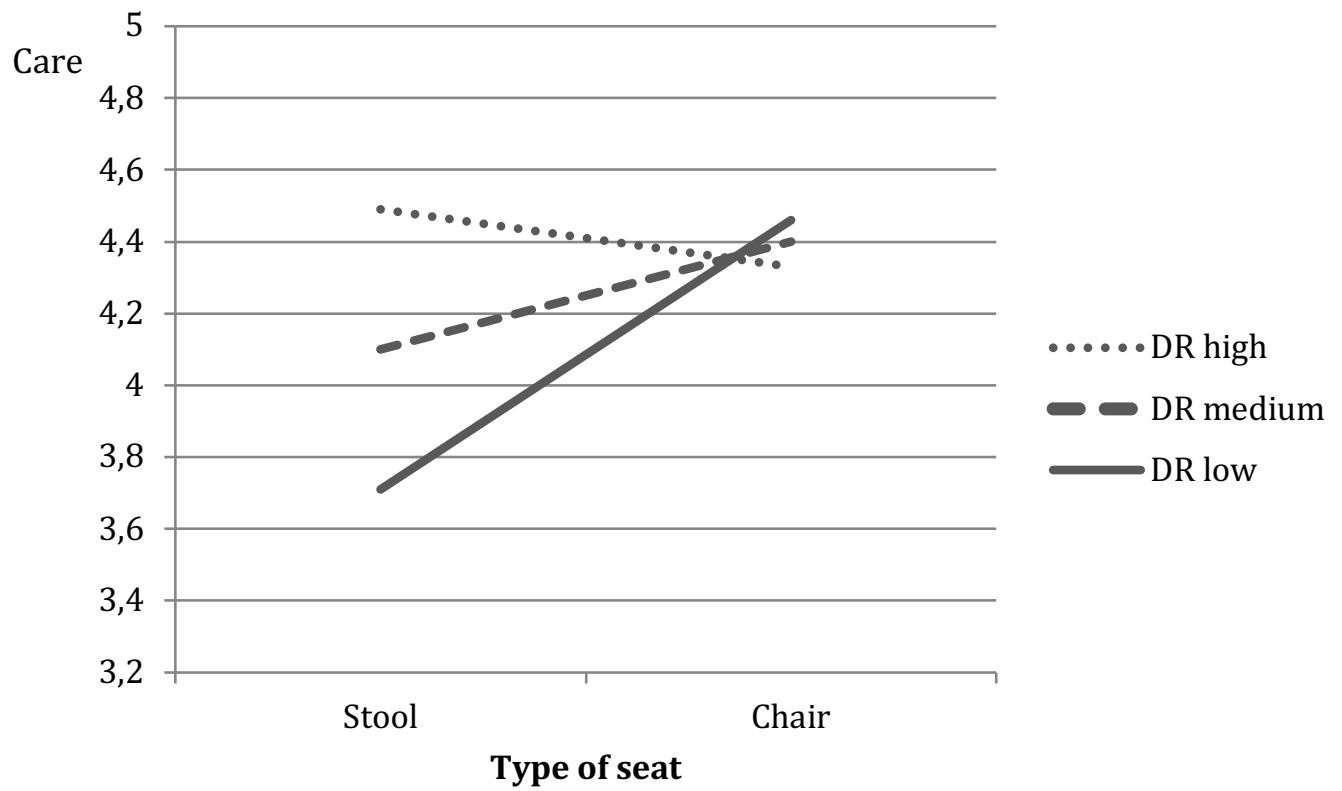

Figure 6. Moderation of desire to relax (DR) in the effect of type of seat on the experience of care.

Thus, in contrast to what was expected the effect of type of seat on the experience of hospitality (care factor) had an effect on a different experiential factor of the hospitality than we expected (care instead on comfort). Furthermore, the effect was stronger for people with a low desire to relax instead for people with a high desire to relax.

Desire to relax did not moderate the effects of type of seat on the other factors of the EH-scale (comfort, inviting and overall EH). Further, it already appeared that there was no direct effect of ambient sound on the experience of hospitality: Desire to relax did not appear to be a moderator in this effect either.

\section{Conclusion and discussion}

The present research shows that attributes related to physical comfort that people perceive sensorial, in this case by touching (seating comfort) and hearing (acoustic comfort), impacts people's experience of hospitality in a service context. The effect of seating comfort was most clear. A comfortable chair, as opposed to an uncomfortable stool, has a positive impact on the experience of 
the comfort factor of people's experience of hospitality.

Despite the difference between the conditions in sound levels ( 2 à $3 \mathrm{dBA}$ ) and the difference in the perceived physical discomfort, the extra ambient sound was not experienced as really uncomfortable. This may be the reason that no direct effect was found of the ambient sound on the experience of hospitality. More research is needed to further investigate the role of physical acoustic comfort in the experience of hospitality. Perhaps in situations with background sound over $75 \mathrm{dBA}$, ambient sound will become more uncomfortable (Chen \& Kang, 2016), which may result in a direct impact of acoustic comfort on the experience of hospitality. However, it will be a challenge to manipulate sound on uncomfortable levels in a natural way in a real-life setting.

However, the interaction between type of seat and ambient sound shows that when exposed to extra kitchen sound, the difference in the experienced hospitality (comfort factor) caused by the difference in comfort of the seats disappears. Although participants perceived the extra kitchen sound as not really uncomfortable, in combination with seating comfort, it was apparently uncomfortable enough to eliminate the positive effect of chair on the comfort factor of the experience of hospitality.

The results provide strong evidence for the idea that embodied cognition is one of the mechanisms in affecting people's experience of hospitality. The mental comfort people experienced in the restaurant fully mediated the effect of the physical comfort of the seats on the experience of hospitality, and specifically on the comfort factor. So the embodied relationship between physical and mental comfort explains the effect of type of seat on the experience of hospitality.

Furthermore, the present study confirms the idea that physical comfort and discomfort are separate constructs. The present study shows that this applies not only to seating comfort, but also to acoustic comfort. Moreover, the present study shows a distinction between physical comfort and mental comfort. This is in line with the factors discomfort, comfort 1 (chair design) and comfort 2 (well-being) of Helander and Zhang (1997), and the physical and psychological items discerned by Da Silva Mengon et al. (2017). Helander and Zhang (1997) and Vink (2005) stated that comfort is mainly associated with experience and emotion, whereas discomfort is associated with physical characteristics and feelings of pain, soreness, numbness and stiffness.

In the present study only physical comfort played a role in the effect of type of seats on the experience of hospitality (comfort factor). However, people had been sitting for a relatively short period (ten to 39 minutes) on the seats, and results showed no relation between the duration people were sitting in the restaurant and physical discomfort. Based on Helander and Zhang (1997), who state that comfort is time independent and discomfort increases over time, discomfort may probably also play a role in the effect, but only when people sit on the seats for a longer period of time, for 
example in a working environment, or a dinner of several hours. Further research is necessary to test this assumption.

Next, the present research supports the findings of others (i.e. Kamp, Kilincsoy, \& Vink, 2011; Mastrigt, Groenesteijn, Vink, \& Kuijt-Evers, 2017) that the perceived physical comfort is related to intentions of the subject. The present research shows that, regardless of the type of seat, the more people desire to sit, the more uncomfortable they perceive the restaurant seats. With regard to the experience of hospitality, the study shows that individual characteristics influence how organisational attributes influence people's the experience of hospitality. People's desire to relax played a role in the effect of type of seat on the experience of hospitality, but unexpectedly on the care factor. Probably people with a low desire to relax are more critical of the furniture, whereas people with a high desire to relax are even happy with an uncomfortable stool.

A second embodied relationship between physical support (seat support) and mental support (part of the care factor) may explain that the effect specifically applies to the care factor: people with a low desire to relax experience less mental support of the organisation when sitting on a stool without physical seat support compared to sitting on a chair with physical seat support.

For practitioners, the findings show that besides human behaviour, also ergonomic aspects contribute to the experience of hospitality. Comfortable furniture may be used to increase the experience of hospitality. The findings can be used for the design of service environments in order to improve the hospitality performance.

\section{References}

Ackerman, J. M., Nocera, C. C., \& Bargh, J. A. (2010). Incidental haptic sensations influence social judgments and decisions. Science, 328(5986), 1712-1715.

http://doi.org/10.1126/science.1189993

Ahola, M., \& Mugge, R. (2017). Safety in passenger ships: The influence of environmental design characteristics on people's perception of safety. Applied Ergonomics, 59(Part A), 143-152. http://doi.org/10.1016/i.apergo.2016.07.021

Ariffin, A., \& Maghzi, A. (2012). A preliminary study on customer expectations of hotel hospitality: Influences of personal and hotel factors. International Journal of Hospitality Management, 31(1), 191-198. http://doi.org/10.1016/i.ijhm.2011.04.012

Asch, S. E. (1958). The metaphor: A psychological inquiry. In R. Tagiuri \& L. Petrullo (Eds.), Person perception and interpersonal behavior (pp. 86-94). Stanford, CA: Stanford University Press. 
Barker, R.T. and Pearce, C.G. (1990). The importance of proxemics at work (space and human comfort in the work environment), Supervisory Management, 35(7), 10-12.

Berry, L. L., Wall, E. A., \& Carbone, L.P. (2006). Service clues and customer assessment of the service experience: lessons from marketing. Academy of Management Perspectives, 20(2), 43-57.

Bitner, M. J. (1992). Servicescapes: the impact of physical surroundings on customers and employees. The Journal of Marketing, 56, 57-71.

Blain, M., \& Lashley, C., (2014). Hospitableness: the new service metaphor? Developing an instrument for measuring hosting. Research in Hospitality Management, 4 (1), 1-8.

Branton, P., \& Grayson, G. (1967). An evaluation of train seats by an observation of sitting behavior. Ergonomics, 10, 35-41.

http://doi.org/10.4135/9781849200417.n2

Brunner-Sperdin, A., Peters, M., \& Strobl, A. (2012). It is all about the emotional state: Managing tourists' experiences. International Journal of Hospitality Management, 31(1), 23-30. http://doi.org/10.1016/i.ijhm.2011.03.004

Cascioli, V., Liu, Z., Heusch, A., \& McCarthy, P. W. (2016). A methodology using in-chair movements as an objective measure of discomfort for the purpose of statistically distinguishing between similar seat surfaces. Applied Ergonomics, 54(C), 100-109.

http://doi.org/10.1016/j.apergo.2015.11.019

Chen, X., \& Kang, J. (2017). Acoustic comfort in large dining spaces. Applied Acoustics, 115(C), 166172. http://doi.org/10.1016/j.apacoust.2016.08.030

da Silva Menegon, L., Vincenzi, S. L., de Andrade, D. F., Barbetta, P. A., Merino, E. A. D., \& Vink, P. (2017). Design and validation of an aircraft seat comfort scale using item response theory. Applied Ergonomics, 62, 216-226. http://doi.org/10.1016/j.apergo.2017.03.005

Fasulo, L., Naddeo, A., \& Cappetti, N. (2018). A study of classroom seat (dis)comfort: Relationships between body movements, center of pressure on the seat, and lower limbs' sensations. Applied Ergonomics, 74, 233-240. http://doi.org/10.1016/j.apergo.2018.08.021

Field, A. (2013). Discovering statistics using IBM SPSS statistics (4th ed.). London: Sage.

Floyd, W. F., \& Ward, J. S. (1969). Anthropometric and physiological considerations in school, office and factory seating. Ergonomics, 12, 132-139.

Frontczak, M., \& Wargocki, P. (2011). Literature survey on how different factors influence human comfort in indoor environments. Building and Environment, 46(4), 922-937. http://doi.org/10.1016/j.buildenv.2010.10.021

George, D., \& Mallery, M. (2010). SPSS for Windows Step by Step: A Simple Guide and Reference, 17.0 
update (10a ed.). Boston: Pearson.

Helander, M. G., \& Zhang, L. (1997). Field studies of comfort and discomfort in sitting. Ergonomics, 40(9), 895-915. http://doi.org/DOI: 10.1080/001401397187739

Hiemstra-van Mastrigt, S., Groenesteijn, L., Vink, P., \& Kuijt-Evers, L. F. M. (2017). Predicting passenger seat comfort and discomfort on the basis of human, context and seat characteristics: a literature review. Ergonomics, 1-23. http://doi.org/10.1080/00140139.2016.1233356

Huizenga, C., Abbaszadeh, S., Zagreus, L., \& Arens, E. A. (2006). Air quality and thermal comfort in office buildings: Results of a large indoor environmental quality survey. Paper presented at the proceeding of healthy buildings, 3, 393-397.

Kamp, I., Kilincsoy, Ü., \& Vink, P. (2011). Chosen postures during specific sitting activities. Ergonomics, 54 (11), 1029-1042. http://doi.org/10.1080/00140139.2011.618230.

Kim, W. G., \& Moon, Y. J. (2009). Customers' cognitive, emotional, and actionable response to the servicescape: A test of the moderating effect of the restaurant type. International Journal of Hospitality Management, 28(1), 144-156. http://doi.org/10.1016/i.ijhm.2008.06.010

Ladeira, W. J., Costa, G., \& Santini, F. D. O. (2013). Background and dimensions of consumption experience in Brazilian hotels. Tourism and Hospitality Research, 12(4), 215-227. http://doi.org/10.1177/1467358413502666

Lam, L. W., Chan, K. W., Fong, D., \& Lo, F. (2011). Does the look matter? The impact of casino servicescape on gaming customer satisfaction, intention to revisit, and desire to stay. International Journal of Hospitality Management, 30(3), 558-567.

http://doi.org/10.1016/j.ijhm.2010.10.003

Lakoff, G., \& Johnson, M. (1980). Metaphors We Live By. Chicago: University of Chicago Press.

Lee, C. J., Wang, Y. C., \& Cai, D. C. (2015). Physical factors to evaluate the servicescape of theme restaurants. Journal of Asian Architecture and Building Engineering, 14(1), 97-104. http://doi.org/10.3130/jaabe.14.97

Lindborg, P. (2016). A taxonomy of sound sources in restaurants. Applied Acoustics, 110(C), 297310. http://doi.org/10.1016/j.apacoust.2016.03.032

Looze, M. P., Kuijt-Evers, L. F., \& van Drieën, J. (2003). Sitting comfort and discomfort and the relationships with objective measures. Ergonomics, 46(10), 985-997.

Lucas, A. F. (2003). The determinants and effects of slot servicescape satisfaction in a Las Vegas Casino. UNLV Gaming Research Review Journal, 7(1), 1-19.

Mastrigt, S. H.-V., Groenesteijn, L., Vink, P., \& Kuijt-Evers, L. F. M. (2017). Predicting passenger seat comfort and discomfort on the basis of human, context and seat characteristics: a literature 
review. Ergonomics, 1-23. http://doi.org/10.1080/00140139.2016.1233356

Mokhtar, M. S. A., Zaoui, L., \& Aid, L. (2014). Bayesian Model of Multisensory Comfort and Adaptation in Intelligent Building. International Journal of Smart Home, 8(5), 125-140. http://doi.org/10.14257/ijsh.2014.8.5.12

Moon, H., Yoon, H. J., \& Han, H. (2017). The effect of airport atmospherics on satisfaction and behavioral intentions: testing the moderating role of perceived safety. Journal of Travel and Tourism Marketing, 34(6), 749-763. http://doi.org/10.1080/10548408.2016.1223779

Murphy, G. L. (1996). On metaphoric representation. Cognition, 60(2), 173-204. http://doi.org/10.1016/0010-0277(96)00711-1

Oborne, D. J. (1987). Ergonomics at work (2nd ed.). Liverpool, UK: Bath Press.

Ong, B. L. 2013. Beyond Environmental Comfort. London: Routledge.

Pijls, R., Groen, B. H., Galetzka, M. \& Pruyn, A. T. H. (2017). Measuring the experience of hospitality: scale development and validation. International Journal of Hospitality Management 67, 125-133. http://doi.org/10.1016/j.ijhm.2017.07.008

Preacher, K. J., \& Hayes, A. F. (2004). SPSS and SAS procedures for estimating indirect effects in simple mediation models. Behavior Research Methods, Instruments, \& Computers, 36(4), 717731. http://doi.org/10.3758/BF03206553

Ricciardi, P., \& Buratti, C. (2018). Environmental quality of university classrooms: Subjective and objective evaluation of the thermal, acoustic, and lighting comfort conditions. Building and Environment, 127, 23-36. http://dx.doi.org/10.1016/i.buildenv.2017.10.030

Richards, L. G. (1980). On the psychology of passenger comfort. In D. J. Oborne and J. A Levis (eds), Human Factors in Transport Research (pp. 15-23) London: Academic Press.

Rijal, H. B., Humphreys, M. A., \& Nicol, J. F. (2017). Towards an adaptive model for thermal comfort in Japanese offices. Building Research \& Information, 45(7), 717-729.

http://dx.doi.org/10.1080/09613218.2017.1288450

Slater, K. (1985). Human comfort, Springfield, IL: Thomas.

Tasci, A. D. A., \& Semrad, K. J. (2016). Developing a scale of hospitableness: A tale of two worlds. International Journal of Hospitality Management, 53, 30-41. http://doi.org/10.1016/i.ijhm.2015.11.006

Vink, P. (2005). Comfort and design principles and good practice. Boca Raton, FL: CRC Press. Wagner, A., Gossauer, E., Moosmann, C., Gropp, T., \& Leonhart, R. (2007). Thermal comfort and workplace occupant satisfaction-Results of field studies in German low energy office buildings. Energy and Buildings, 39(7), 758-769. doi: 10.1016/j.enbuild.2007.02.013 
Wakefield, K. L., \& Blodgett, J. G. (1996). The effect of the servicescape on customers' behavioral intentions in leisure service settings. Journal of Services Marketing, 10(6), 45-61. http://doi.org/10.1108/08876049610148594

Williams, L. E., Huang, J. Y., \& Bargh, J. A. (2009). The scaffolded mind: Higher mental processes are grounded in early experience of the physical world. European Journal of Social Psychology, 39(7), 1257-1267. http://doi.org/10.1002/ejsp.665

Zhang, L., Helander, M., \& Drury, C. G. (1996). Identifying factors of comfort and discomfort in seating. Human Factors, 38, 377 - 389.

Zhao, X., Lynch, J. G., \& Chen, Q. (2010). Reconsidering Baron and Kenny: Myths and truths about mediation analysis. Journal of Consumer Research, 37(2), 197-206. http://doi.org/10.1086/651257

Zheng, M. C. (2014). How airport users luggage affects their perception of seat design at airports. Journal of Asian Architecture and Building Engineering, 13(1), 141-148. http://doi.org/10.3130/jaabe.13.141 


\section{Appendix A}

Rotated Factor Matrix (PCA, varimax rotation, $\mathrm{n}=262)$ and communalities $\left(\mathrm{h}^{2}\right)$.

\begin{tabular}{|c|c|c|c|c|c|c|}
\hline Item & $\mathbf{h}^{2}$ & & r loadi & & & \\
\hline & & 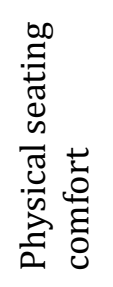 & 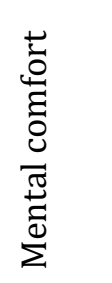 & 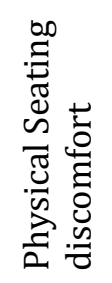 & 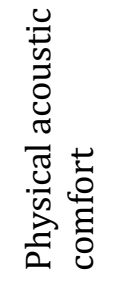 & 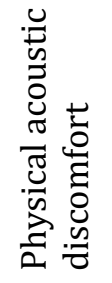 \\
\hline Furniture suits body & .88 & .92 & & & & \\
\hline furniture sits comfortable & .79 & .91 & & & & \\
\hline furniture sits easily & .87 & .90 & & & & \\
\hline furniture supports body & .81 & .87 & & & & \\
\hline furniture sits well & .87 & .85 & & & & \\
\hline furniture feels warm & .64 & .74 & & & & \\
\hline able to relax body & .53 & .68 & & & & \\
\hline furniture is sturdy & .54 & .68 & & & & \\
\hline able to sit comfortably for hours & .48 & .62 & & & & \\
\hline body feels tired & .85 & & & .88 & & \\
\hline body feels stiff & .83 & & & .88 & & \\
\hline feel uneven pressure & .71 & & & .82 & & \\
\hline feeling comfortable & .88 & & .90 & & & \\
\hline Feeling relaxed & .87 & & .88 & & & \\
\hline Able to rest & .81 & & .84 & & & \\
\hline feeling good & .78 & & .84 & & & \\
\hline feeling refreshed & .78 & & .82 & & & \\
\hline recovering & .76 & & .82 & & & \\
\hline hearing much kitchen sounds & .82 & & & & .89 & \\
\hline suffering from kitchen sounds & .84 & & & & .90 & \\
\hline ambient sounds are exhausting & .61 & & & & .60 & \\
\hline Intelligibility conversation partner & .56 & & & & & .76 \\
\hline pleasantness ambient sounds & .64 & & & & & .76 \\
\hline Eigenvalue & & 8.95 & 2.86 & 2.70 & 1.45 & 1.18 \\
\hline$\%$ of variance & & 38.90 & 12.43 & 11.74 & 6.28 & 5.12 \\
\hline Cumulative $\%$ of variance & & 38.90 & 51.33 & 63.07 & 69.35 & 74.47 \\
\hline Internal Consistency (Cronbach's $\alpha$ ) & & $\alpha=.94$ & $\alpha=.95$ & $\alpha=.85$ & $\alpha=.78$ & $\alpha=.50$ \\
\hline
\end{tabular}

Note: Items have been translated from Dutch. 


\section{Appendix B}

Items Seating and Acoustics Comfort

\begin{tabular}{ll}
\hline Item & Comfort Factor \\
\hline In my opinion this furniture suits my body & Physical seating comfort \\
In my opinion this furniture sits comfortable & Physical seating comfort \\
In my opinion this furniture sits easily & Physical seating comfort \\
In my opinion this furniture supports my body & Physical seating comfort \\
In my opinion this furniture sits well & Physical seating comfort \\
In my opinion this furniture feels warm & Physical seating comfort \\
Sitting on this furniture I can relax my body well & Physical seating comfort \\
In my opinion this furniture is sturdy & Physical seating comfort \\
I can sit comfortably on this furniture for hours & Physical seating comfort \\
Sitting on this furniture I my body feels tired & Physical seating discomfort \\
Sitting on this furniture I my body feels stiff & Physical seating discomfort \\
Sitting on this furniture I feel uneven pressure & Physical seating discomfort \\
Sitting at this place in the restaurant I can hear my conversation partners well & Physical acoustic comfort \\
Sitting at this place in the restaurant the sounds are pleasant & Physical acoustic comfort \\
Sitting at this place in the restaurant I hear much kitchen sound & Physical acoustic discomfort \\
Sitting at this place in the restaurant I suffer from the kitchen sounds & Physical acoustic discomfort \\
Sitting at this place in the restaurant the ambient sounds are exhausting me & Physical acoustic discomfort \\
Sitting at this place in the restaurant I feel comfortable & Mental comfort \\
Sitting at this place in the restaurant I feel relaxed & Mental comfort \\
Sitting at this place in the restaurant I can rest & Mental comfort \\
Sitting at this place in the restaurant I feel good & Mental comfort \\
Sitting at this place in the restaurant I feel refreshed & Mental comfort \\
Sitting at this place in the restaurant I recover & Mental comfort \\
\hline
\end{tabular}

Note: Items have been translated from Dutch. 